\section{A) Check for updates}

Cite this: Org. Chem. Front., 2021, 8 , 3280

Received 11th February 2021,

Accepted 31st March 2021

DOI: 10.1039/d1qo00251a

rsc.li/frontiers-organic

\title{
Mild reductive rearrangement of oximes and oxime ethers to secondary amines with hydrosilanes catalyzed by $\mathrm{B}\left(\mathrm{C}_{6} \mathrm{~F}_{5}\right)_{3} \dagger$
}

\author{
Huaquan Fang, (D) $\ddagger^{a}$ Guoqiang Wang (D) $\ddagger^{a, b}$ and Martin Oestreich (D) *a
}

The strong boron Lewis acid tris(pentafluorophenyl)borane, $\mathrm{B}\left(\mathrm{C}_{6} \mathrm{~F}_{5}\right)_{3}$, has been found to catalyze the reductive rearrangement of oximes and their ether derivatives at room temperature with hydrosilanes as the reducing agents. Cyclic substrates undergo ring enlargement, and the secondary amine products are generally formed in good yields. Control experiments combined with a DFT computational analysis of the reaction mechanism suggest that there are three energetically accessible reaction pathways (paths $A-C$ ), either or not involving hydroxylamine derivatives. Paths A and B proceed through the intermediacy of a common $\mathrm{N}, \mathrm{O}$-bissilylated hydroxylamine, and the ring-expanding rearrangement yields an iminium ion. With no intermediate at the hydroxylamine oxidation level (path $\mathrm{C}$ ), the reaction mechanism resembles that of the Beckmann rearrangement where an $O$-silylated oxime converts into a nitrilium ion. The reduction-rearrangement sequence (paths $\mathrm{A}$ and $\mathrm{B}$ ) is slightly preferred over the rearrangementreduction order of events (path $\mathrm{C}$ ), especially at ambient temperature.

\section{Introduction}

A few years ago, our laboratory disclosed the previously elusive hydrogenation of various oxime ethers to the corresponding $O$-protected hydroxylamines by making use of FLP-type dihydrogen activation with $\mathrm{B}\left(\mathrm{C}_{6} \mathrm{~F}_{5}\right)_{3}$ as the catalyst ${ }^{1}$ (Scheme 1, top). ${ }^{2}$ The goal of that project had been to avoid the otherwise typical cleavage of the weak $\mathrm{N}-\mathrm{O}$ bond to afford primary amines. ${ }^{3}$ For this, the use of dihydrogen is critical because hydrosilanes as alternative reductants ${ }^{4}$ engage in deoxygenation. ${ }^{5}$ Treatment of those oxime ethers with hydrosilane/ $\mathrm{B}\left(\mathrm{C}_{6} \mathrm{~F}_{5}\right)_{3}$ combinations results in exactly that, and these reactions were not clean but there was evidence for a reductive rearrangement. ${ }^{2 a}$ Rearrangements of this sort that convert oximes and their ether derivatives into secondary amines can be achieved by the stoichiometric use of aluminum $-{ }^{6}$ and also boron-based $^{7}$ reductants; the aforementioned reduction to primary amines is a common side reaction (Scheme 1, bottom). In the light of our earlier observations, we decided to investigate the $\mathrm{B}\left(\mathrm{C}_{6} \mathrm{~F}_{5}\right)_{3}$-catalyzed reductive rearrangement of

\footnotetext{
${ }^{a}$ Institut für Chemie, Technische Universität Berlin, Strasse des 17. Juni 115, 10623 Berlin, Germany. E-mail: martin.oestreich@tu-berlin.de

${ }^{b}$ Institute of Theoretical and Computational Chemistry, School of Chemistry and Chemical Engineering, Nanjing University, Nanjing, 210023, P.R. China

$\dagger$ Electronic supplementary information (ESI) available: Experimental details, characterization and computational data. See DOI: 10.1039/d1qo00251a $\$$ These authors contributed equally to this work.
}

oximes with hydrosilanes to turn it into a useful chemoselective methodology.

\section{Results and discussion}

We began our investigations with optimizing the reductive rearrangement of $\alpha$-tetralone-derived oxime into the corresponding 2,3,4,5-tetrahydro- $1 H$-benzo[ $b]$ azepine $[(E)$-1aa $\rightarrow \mathbf{2 a}$; Table 1]. Treatment of $(E)$-1aa with 4.0 equiv. of $\mathrm{PhSiH}_{3}$ in the presence of $10 \mathrm{~mol} \%$ of $\mathrm{B}\left(\mathrm{C}_{6} \mathrm{~F}_{5}\right)_{3}$ in $1,2-\mathrm{C}_{6} \mathrm{H}_{4} \mathrm{~F}_{2}$ at room temperature afforded 2a in $40 \%$ yield after $20 \mathrm{~h}$ (entry 1 ). This reaction was highly chemoselective, favoring migration of the aryl group over simple reduction; no formation of any primary

$$
\begin{aligned}
& \text { Reduction of oxime ether with no N-O cleavage (2014/2015) }
\end{aligned}
$$

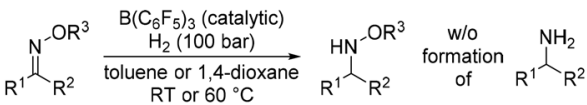

$$
\begin{aligned}
& \text { Reductive rearrangement of oximes and oxime ethers (this work) }
\end{aligned}
$$

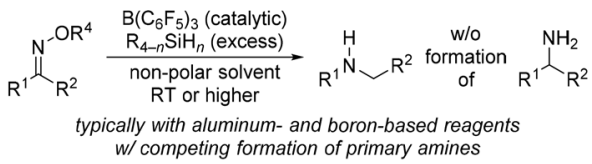

Scheme 1 Reduction and reductive rearrangement of oximes and

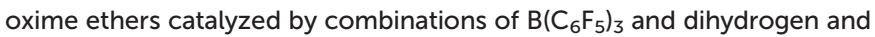
hydrosilanes $(n=1-3)$, respectively. $\mathrm{R}^{1}$ and $\mathrm{R}^{2}=$ aryl, alkyl, and $\mathrm{H} ; \mathrm{R}^{3}=$ alkyl or silyl; $\mathrm{R}^{4}=$ alkyl, silyl, or $\mathrm{H}$. 
Table 1 Selected examples of the optimization of $B\left(C_{6} F_{5}\right)_{3}$-catalyzed reductive rearrangement ${ }^{a}$

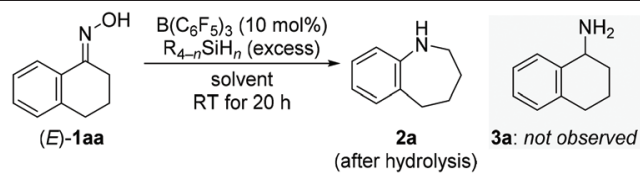

\begin{tabular}{llll}
\hline Entry & Hydrosilane (equiv.) & Solvent & Yield $^{b}(\%)$ \\
\hline 1 & $\mathrm{PhSiH}_{3}(4.0)$ & $1,2-\mathrm{C}_{6} \mathrm{H}_{4} \mathrm{~F}_{2}$ & 40 \\
2 & $\mathrm{PhSiH}_{3}(4.0)$ & $\mathrm{C}_{6} \mathrm{H}_{5} \mathrm{~F}$ & 64 \\
3 & $\mathrm{PhSiH}_{3}(4.0)$ & $\mathrm{C}_{6} \mathrm{H}_{5} \mathrm{Cl}$ & 69 \\
4 & $\mathrm{PhSiH}_{3}(4.0)$ & $\mathrm{CH}_{2} \mathrm{Cl}_{2}$ & 66 \\
5 & $\mathrm{PhSiH}_{3}(4.0)$ & Benzene & 88 \\
6 & $\mathrm{PhSiH}_{3}(4.0)$ & Toluene- $d_{8}$ & $95(88)$ \\
7 & $\mathrm{MePhSiH}_{2}(4.0)$ & Toluene- $d_{8}$ & 95 \\
8 & $\mathrm{Ph}_{2} \mathrm{SiH}_{2}(4.0)$ & Toluene- $d_{8}$ & 77 \\
9 & $\mathrm{Et}_{2} \mathrm{SiH}_{2}(4.0)$ & Toluene- $d_{8}$ & 0 \\
10 & $\mathrm{Me}_{2} \mathrm{PhSiH}^{2}(4.0)$ & Toluene- $d_{8}$ & 0 \\
$11^{c}$ & $\mathrm{PhSiH}_{3}(4.0)$ & Toluene- $d_{8}$ & 67 \\
12 & $\mathrm{PhSiH}_{3}(2.0)$ & Toluene- $d_{8}$ & 80 \\
$13^{d}$ & $\mathrm{PhSiH}_{3}(4.0)$ & Toluene- $d_{8}$ & 78
\end{tabular}

${ }^{a}$ All reactions were performed on a $0.10 \mathrm{mmol}$ scale in a GC vial. ${ }^{b}$ Yields determined by ${ }^{1} \mathrm{H}$ NMR spectroscopy using mesitylene as an internal standard; isolated yield in parentheses. ${ }^{c} 8 \mathrm{~h} .{ }^{d} 5.0 \mathrm{~mol} \%$ $\mathrm{B}\left(\mathrm{C}_{6} \mathrm{~F}_{5}\right)_{3}$.

amine product 3a was detected (gray box). Among several solvents tested, toluene (toluene- $d_{8}$ used) brought about the best result with $95 \%$ yield and $88 \%$ isolated yield (entries $2-6$ ). In toluene- $d_{8}$, excellent and good yields were also obtained with $\mathrm{MePhSiH}_{2}$ and $\mathrm{Ph}_{2} \mathrm{SiH}_{2}$, respectively (entries 7 and 8). Other hydrosilanes such as $\mathrm{Et}_{2} \mathrm{SiH}_{2}$ and $\mathrm{Me}_{2} \mathrm{PhSiH}$ were however completely unreactive even at higher temperature (entries 9 and 10, see the ESI $\dagger$ for details). Reactions conducted with a shorter reaction time (entry 11), less $\mathrm{PhSiH}_{3}$ (entry 12), or decreased catalyst loading (entry 13) resulted in lower yields. Incomplete conversion at reduced catalyst loadings could be compensated by longer reaction times.

The yield of the above reductive rearrangement was also high on a $7.0 \mathrm{mmol}$ scale, and we continued exploring the reaction scope under this optimized reaction setup (Scheme 2; $c f$. Table 1, entry 6). Related ring enlargements worked equally well $[(E)-\mathbf{1} \mathbf{b a}, \mathbf{c a} \rightarrow \mathbf{2 b}, \mathbf{c}]$. The functional-group tolerance was assessed with acetophenone-derived oxime derivatives $(E)$-1dapa bearing a range of electron-donating and electron-withdrawing substituents on the aryl group. The four halo groups as in $(E)$-1ia-la were compatible with the reaction conditions but aryl iodide $(E)$-1la underwent partial hydrodeiodination to afford $2 \mathbf{l}$ in $57 \%$ yield along with $2 \mathrm{~d}$ in $25 \%$ yield. A thioether as in $(E)$-1na and a free phenol as in $(E)$-1oa undergoing temporary silylation were tolerated as well. Exhaustive hydrodefluorination of the trifluoromethyl group in $(E)$-1ma occurred, furnishing $\mathbf{2 h}$ rather than $\mathbf{2 m}{ }^{8}$ The reaction of $(E)-\mathbf{1 p a}$ with a dimethylamino group in the para position only gave a trace amount of $2 \mathbf{p}$, and the deamination product 4 -ethyl- $N, N$-dimethylaniline was formed in $64 \%$ yield. ${ }^{9}$ It is important to note that the configuration of the oxime does not affect the

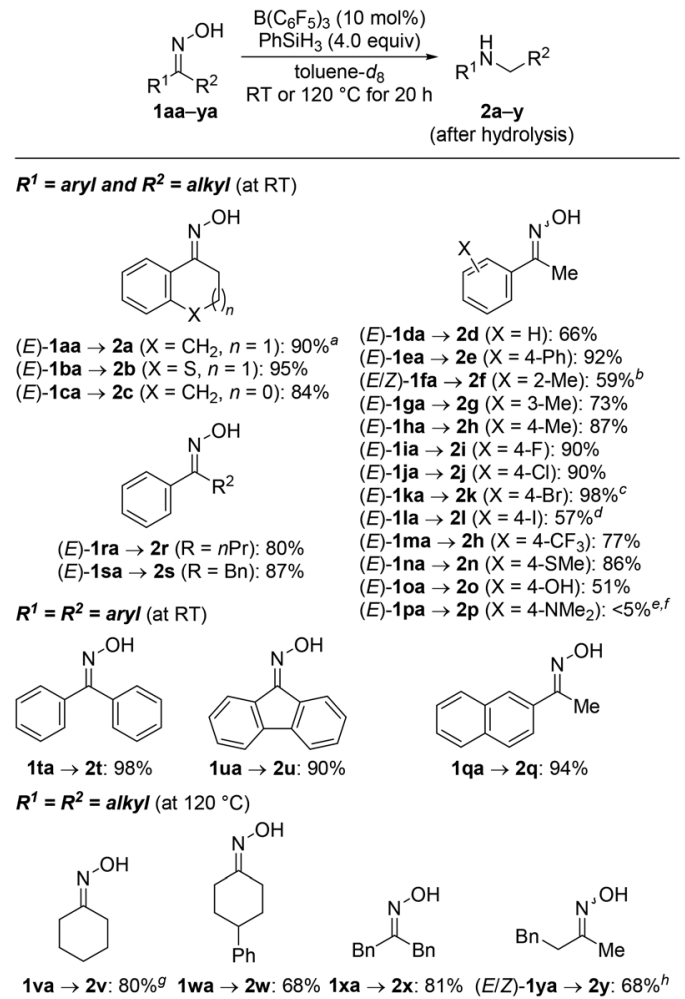

Scheme 2 Scope I: $B\left(C_{6} F_{5}\right)_{3}$-catalyzed reductive rearrangement of ketone-derived oximes. Reaction conditions: $1(0.20 \mathrm{mmol}), \mathrm{B}\left(\mathrm{C}_{6} \mathrm{~F}_{5}\right)_{3}$ (10 mol\%), $\mathrm{PhSiH}_{3}$ (4.0 equiv.), and toluene- $d_{8}(0.20 \mathrm{~mL})$ at RT for $20 \mathrm{~h}$. Isolated yields after purification by flash chromatography on silica gel. ${ }^{a} 7.0 \mathrm{mmol}$ scale. ${ }^{b} E / Z=75: 25$ for 1 fa. ${ }^{c} 93 \%$ yield for $(Z)-1 \mathrm{ka}$. ${ }^{d}$ Formed along with $2 \mathrm{~d}$ in $25 \%$ yield. ${ }^{e}$ Run at $120{ }^{\circ} \mathrm{C}$. ${ }^{f} 4$-Ethyl-N,N-dimethylaniline formed in $64 \%$ yield. ${ }^{9}$ Determined by ${ }^{1} \mathrm{H}$ NMR spectroscopy using mesitylene as an internal standard. ${ }^{h} E / Z=71: 29$ for 1ya.

reaction outcome; ${ }^{6 g}$ both $(E)$-1 ka and $(Z)-1 \mathbf{k a}$ yielded $2 \mathbf{k}$ in $98 \%$ and $93 \%$, respectively.

We briefly investigated the reductive rearrangement of other alkyl-substituted benzylic oximes (Scheme 2). (E)-1ra and (E)-1sa with a $1^{\circ}$ alkyl and a benzylic substituent converted selectively and in high yields into the corresponding secondary amines. However, substrates with $2^{\circ}$ and $3^{\circ}$ alkyl groups did lead to mixtures of rearranged products because the migrating ability of these groups (out)competes with that of the aryl group. This finding is different from previous reports. ${ }^{6 g}$ The results obtained with isopropyl, cyclohexyl, and tert-butyl are presented in the ESI. $\dagger$ Symmetric ketoximes such as diarylsubstituted 1ta and 1ua as well as dialkyl-substituted 1va-xa reacted cleanly but for the latter a reaction temperature of $120{ }^{\circ} \mathrm{C}$ was necessary to achieve high conversion. The rearrangement of unsymmetrically substituted $(E / Z)-1$ ya furnished $2 \mathrm{y}$ selectively with migration of the phenethyl group. Additional substrates were subjected to the standard procedure (Scheme 3). Aldoxime (E)-1za rearranged to the aniline derivative $2 \mathrm{z}$ in a good yield. Moreover, diamine 5 was obtained from bisoxime $(Z, Z)-4$ by two-fold rearrangement in a moderate yield. 


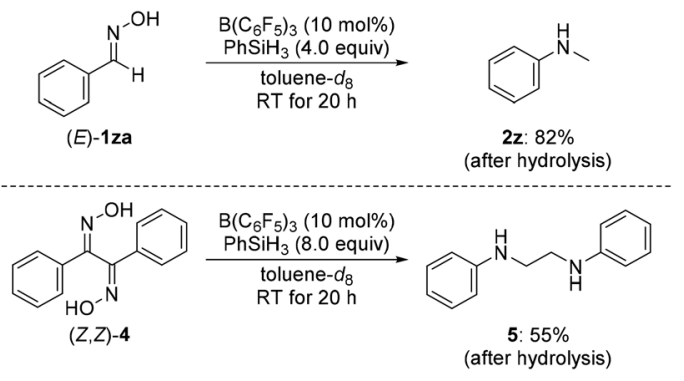

Scheme 3 Scope II: $B\left(\mathrm{C}_{6} \mathrm{~F}_{5}\right)_{3}$-catalyzed reductive rearrangement of aldehyde- and benzil-derived oximes. Isolated yields after purification by flash chromatography on silica gel.

We then turned our attention towards the reductive rearrangement of various oxime ethers (Scheme 4). After a slight reoptimization of the reaction conditions, we found that the reaction of $O$-silylated $(E)$-1db-de and $O$-alkylated ketoximes $(E)$-1df and $(E)-\mathbf{1 d g}$ with 2.0 equiv. of $\mathrm{PhSiH}_{3}$ in the presence of $2.5 \mathrm{~mol} \%$ of $\mathrm{B}\left(\mathrm{C}_{6} \mathrm{~F}_{5}\right)_{3}$ afforded $N$-ethylaniline (2d) in moderate to near-quantitative yields. The scope also includes the successful reductive rearrangement of hydroxylamine $6 \mathbf{a a}$ and $O$-silylated hydroxylamine 7de (Scheme 5). Both yielded the desired secondary amines $2 \mathrm{a}$ and $2 \mathrm{~d}$ in $61 \%$ and $81 \%$, respectively.

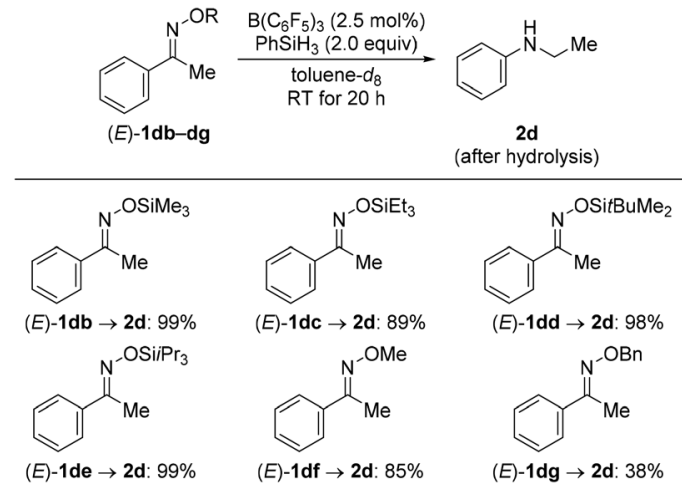

Scheme 4 Scope III: $\mathrm{B}\left(\mathrm{C}_{6} \mathrm{~F}_{5}\right)_{3}$-catalyzed reductive rearrangement of ketone-derived oxime ethers. Yields determined by ${ }^{1} \mathrm{H}$ NMR spectroscopy using mesitylene as an internal standard.

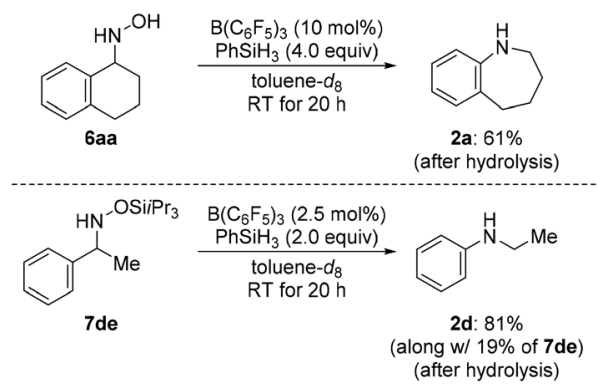

Scheme 5 Scope IV: $\mathrm{B}\left(\mathrm{C}_{6} \mathrm{~F}_{5}\right)_{3}$-catalyzed reductive rearrangement of a hydroxylamine and an $\mathrm{O}$-silylated hydroxylamine. Yields determined by ${ }^{1} \mathrm{H}$ NMR spectroscopy using mesitylene as an internal standard.
The hydroxylamine derivatives were not only chosen as an expansion of the method but also for their potential intermediacy in the reductive rearrangement of oximes. The above results indicate that $O$-silylated oximes, free hydroxylamines, and $O$-silylated hydroxylamines may be involved. Further evidence came from deuterium labeling when employing $\mathrm{PhSiD}_{3}$ instead of $\mathrm{PhSiH}_{3}$ (Scheme 6). Bisdeuteration of the $\alpha$-methylene group was obtained in the rearrangement of the oxime $\left[(E)\right.$-1aa $\left.\rightarrow \mathbf{2 a}-d_{2}\right]$ while monodeuteration was seen in the same position in the ring enlargement of the hydroxylamine (6aa $\left.\rightarrow \mathbf{2 a}-d_{1}\right)$. This suggests that oximes and their congeners are reduced to the hydroxylamine oxidation level during the course of the reaction. ${ }^{2,10}$ Cho, Tokuyama, and coworkers had reported the same for the related DIBAL-Hmediated rearrangement, and their computed mechanism proceeds through a three-centered transition state for the concerted aryl migration followed by hydride reduction of the resulting iminium ion ${ }^{6 g}$ (silyliminium ion in the case of hydrosilane $/ \mathrm{B}\left(\mathrm{C}_{6} \mathrm{~F}_{5}\right)_{3}$ combinations).

We then conducted density functional calculations (DFT) to explore the mechanistic details of the reductive rearrangement of oximes to secondary amines. The calculations were performed at the M06-2X/cc-pVTZ//M06-2X/6-311G(d,p) level of theory $^{11}$ using the Gaussian 16 software, ${ }^{12}$ with toluene solvation incorporated via a polarizable continuum model (PCM) at the same level of theory. ${ }^{13}$ The reaction between oxime $(E)$ 1aa and $\mathrm{PhSiH}_{3}$ was chosen as a model system. Optimized geometries and free energy profiles (including the computational analysis on the relative stability of the $\mathrm{B}\left(\mathrm{C}_{6} \mathrm{~F}_{5}\right)_{3} \cdot(E)$-1aa Lewis pair and the $\mathrm{B}\left(\mathrm{C}_{6} \mathrm{~F}_{5}\right)_{3}$.hydrosilane $\eta^{1}$-adduct $\left.\mathbf{I 1}^{14}\right)$ involved in the catalytic cycle are provided in the ESI. $\dagger^{15}$

As shown in Scheme 7, the reaction begins with the activation of the $\mathrm{Si}-\mathrm{H}$ bond in $\mathbf{I 1}$ by the nitrogen atom or oxygen atom in oxime $(E)-\mathbf{1 a a}{ }^{16,17}$ to afford $N$-silyliminium ion $\mathbf{I 2}$ (path A) or silyloxonium ion I8 (path $\mathrm{B}$ ) with the borohydride $\left[\mathrm{HB}\left(\mathrm{C}_{6} \mathrm{~F}_{5}\right)_{3}\right]^{-}$as the counteranion. Our calculations indicate that the corresponding $\mathrm{S}_{\mathrm{N}} 2$-Si transition states do not exist in the case of $\mathrm{PhSiH}_{3} \cdot{ }^{17,18}$ Instead, two stable trigonal bipyramidal transition complexes (rather than transition state) were located (I2' or I8', see Fig. S70 in the ESI $\dagger$ ). ${ }^{19}$ These results are different from that found in a computational study on $\mathrm{B}\left(\mathrm{C}_{6} \mathrm{~F}_{5}\right)_{3}$-catalyzed carbonyl hydrosilylation with a tertiary silane $\left(\mathrm{Me}_{3} \mathrm{SiH}\right) .{ }^{17}$ Subsequent hydride transfer from the borohydride to the silyliminium ion or dehydrogenation gives the $\mathrm{N}$-silylated hydroxylamine $(\mathbf{I} 2 \rightarrow \mathbf{I 3})$ and $\mathrm{O}$-silylated oxime

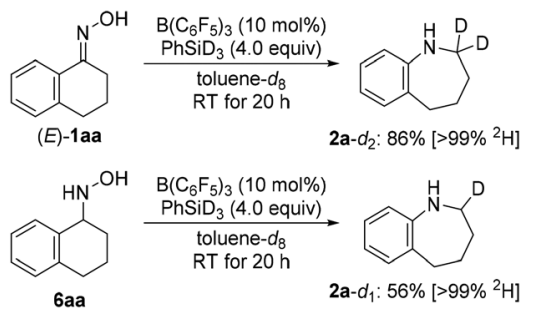

Scheme 6 Deuterium-labeling experiments. 


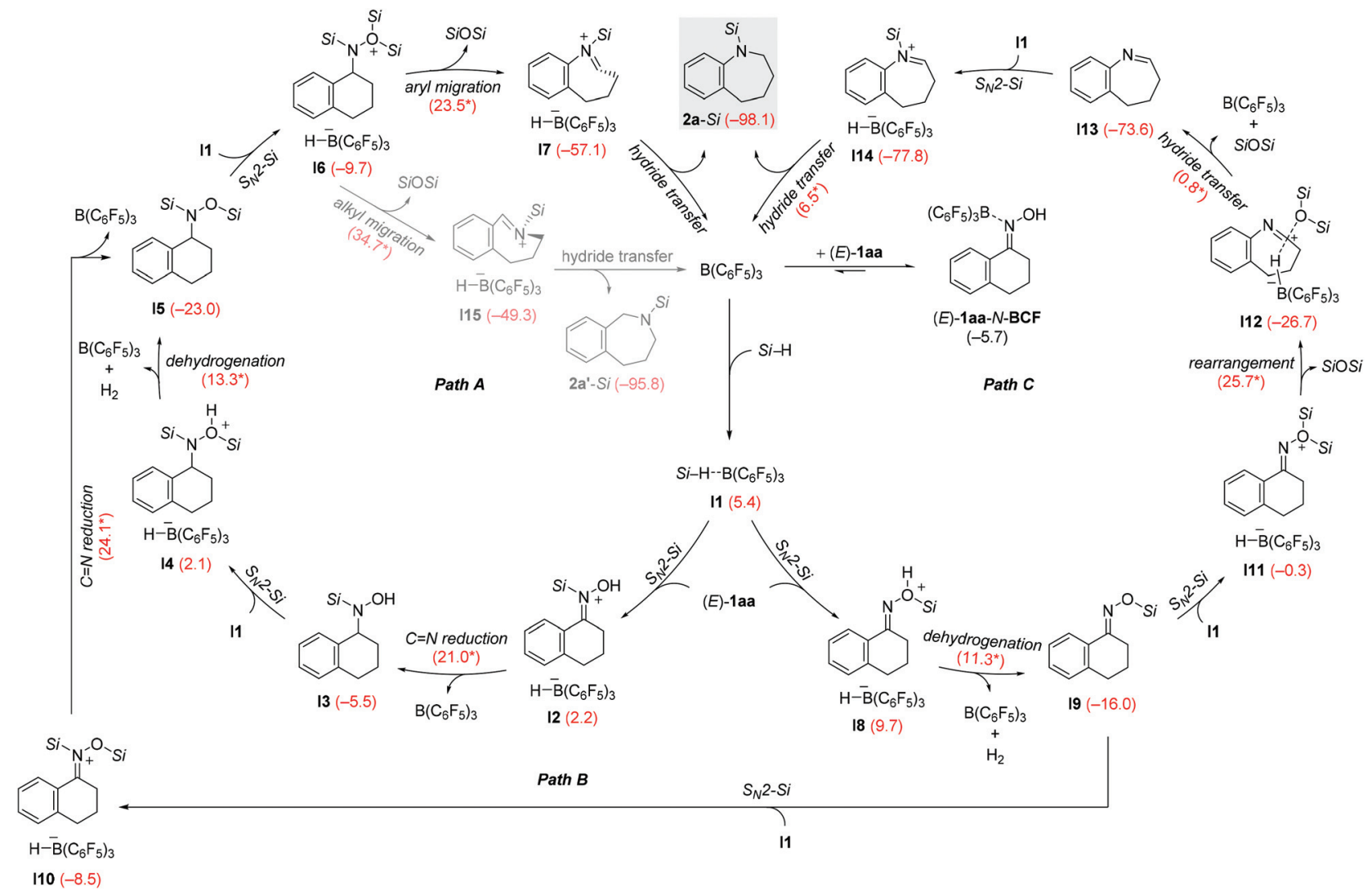

Scheme 7 Reaction pathways for the reductive rearrangement of oximes to secondary amines calculated with the M06-2X functional. For each step, the Gibbs free reaction energies and barriers (labeled with an asterisk) are in $\mathrm{kcal} \mathrm{mol}^{-1}$. $\left(\mathrm{Si}=\mathrm{SiH}_{2} \mathrm{Ph}, \mathrm{S}_{\mathrm{N}} 2-\mathrm{Si}=\right.$ nucleophilic substitution at silicon).

ether $(\mathbf{I 8} \rightarrow \mathbf{I} \mathbf{9})$, respectively. $\mathrm{B}\left(\mathrm{C}_{6} \mathrm{~F}_{5}\right)_{3}$ is regenerated in either of these steps. The formation of $O$-silylated oxime ether $\mathbf{I 9}$ is favored over $N$-silylated hydroxylamine $\mathbf{I} 3$ because the dehydrogenative silylation of oxime $(E)$-1aa is calculated to be kinetically more favorable than the $\mathrm{C}=\mathrm{N}$ hydrosilylation reaction $\left(\Delta G^{\ddagger}=11.3\right.$ versus $\left.21.0 \mathrm{kcal} \mathrm{mol}^{-1}\right)$, probably due to the release of dihydrogen gas. The $N$-silylated hydroxylamine $\mathbf{I 3}$ or $\mathrm{O}$-silylated oxime $\mathbf{I 9}$ then undergoes similar dehydrogenative silylation or $\mathrm{C}=\mathrm{N}$ hydrosilylation steps to form $\mathrm{N}, \mathrm{O}$-bissilylated hydroxylamine I5 through either I3 $\rightarrow$ I4 $\rightarrow$ I5 (path A) or I9 $\rightarrow$ I10 $\rightarrow$ I5 (path B). The hydrosilylation of $O$-silylated oxime ether 19 requires an activation barrier of $24.1 \mathrm{kcal}$ $\mathrm{mol}^{-1}$, which is higher than that of the dehydrogenative silylation reaction of $\mathbf{I} 3\left(\Delta G^{\ddagger}=13.3 \mathrm{kcal} \mathrm{mol}^{-1}\right)$. These computational results suggest that the formation of $\mathrm{N}, \mathrm{O}$-bissilylated hydroxylamine $\mathbf{I} 5$ proceeding through $\mathrm{C}=\mathrm{N}$ hydrosilylation $/ \mathrm{Si}-$ O dehydrogenative coupling (path A) is the dominant reaction sequence in the current system. $\mathbf{I} 5$ could further react with the $\mathrm{B}\left(\mathrm{C}_{6} \mathrm{~F}_{5}\right)_{3}$.hydrosilane adduct $\mathbf{I} \mathbf{1}$ to form ion pair $\mathbf{I 6}$, which undergoes the rearrangement involving aryl migration and $\mathrm{N}-$ O bond cleavage to generate the iminium ion $\mathbf{I 7}$ along with the disiloxane byproduct $\left(\mathbf{I} 6 \rightarrow \mathbf{I} 7, \Delta G^{\ddagger}=23.5 \mathrm{kcal} \mathrm{mol}{ }^{-1}\right){ }^{20}$ Finally, $\mathbf{I 7}$ further reacts through a barrierless hydride transfer process from the borohydride to the iminium ion to form the reductive rearrangement product $2 \mathrm{a}-\mathrm{Si}$ (gray box). The overall reaction is exergonic by $98.1 \mathrm{kcal} \mathrm{mol}^{-1}$, and both path A and path $\mathrm{B}$ are likely related to the formation of the reductive rearrangement product because of the close activation barriers in the rate-determining steps involved (path A, I6 $\rightarrow \mathbf{I 7}, \Delta G^{\ddagger}=$ $23.5 \mathrm{kcal} \mathrm{mol}{ }^{-1}$; path B, I10 $\rightarrow \mathbf{I 5}, \Delta G^{\ddagger}=24.1 \mathrm{kcal} \mathrm{mol}^{-1}$ ). These computational results can account for the experimental observation that oxime ethers and several hydroxylamine derivatives are also applicable to this method.

We also considered the possibility of the classical Beckmann rearrangement ${ }^{21}$ (path C, see Fig. S68 and S69 in the ESI $\dagger$ for details). This pathway proceeds through the reaction of $\mathbf{I} \mathbf{9}$ with the $\mathrm{B}\left(\mathrm{C}_{6} \mathrm{~F}_{5}\right)_{3}$.hydrosilane adduct $\mathbf{I} \mathbf{1}$ to form the bissilyloxonium ion I11 with the oxygen atom as the nucleophilic center. Aryl migration and $\mathrm{N}-\mathrm{O}$ bond cleavage of I11 further leads to the formation of ternary complex I12, in which both the borohydride and the disiloxane are loosely bound to the carbon atom of the nitrilium ion (see Fig. S69† for the structural details of I12). Subsequent hydride reduction accompanied by disiloxane displacement yields the ringexpanded imine $\mathbf{I} 13$ along with $\mathrm{B}\left(\mathrm{C}_{6} \mathrm{~F}_{5}\right)_{3}$. A subsequent imine hydrosilylation ${ }^{10}$ through $N$-silyliminium ion $\mathbf{I 1 4}$ furnishes the reductive rearrangement product $2 \mathrm{a}-\mathrm{Si}$ (gray box). The ratedetermining step of this pathway is the aryl migration/N-O bond cleavage in intermediate $\mathbf{I 1 1}$ with an activation barrier of $25.7 \mathrm{kcal} \mathrm{mol}^{-1}$. Although this process is kinetically less favorable than path A or B, we cannot exclude whether this pathway contributes to the formation of the related reductive rearrange- 
ment product, especially in cases where higher reaction temperatures are applied.

The direct hydride transfer from the borohydride to the nitrogen atom of intermediate I6 or I11 to eventually form the primary amine $\mathbf{3 a}$ is kinetically disfavoured ( $c f$. gray box in Table 1). The corresponding barriers are estimated to be at least 65.9 and $47.6 \mathrm{kcal} \mathrm{mol}^{-1}$, respectively (relative to separated reactants; see Fig. S64, S68, and S72†). These results can account for the high selectivity in favor of the secondary amine 2a under the experimental conditions.

\section{Conclusion}

In summary, we have developed an effective catalytic reductive rearrangement of oximes and their congeners to selectively give secondary amines. Aryl-substituted secondary and primary hydrosilanes work as stoichiometric reductants, and a catalyst loading of 10 or $2.5 \mathrm{~mol} \%$ of $\mathrm{B}\left(\mathrm{C}_{6} \mathrm{~F}_{5}\right)_{3}$ is sufficient to secure synthetically useful yields. Quantum-chemical calculations revealed that this reductive rearrangement can follow two distinct orders of events (Scheme 7): reduction-rearrangement involving hydroxylamine derivatives (paths A and B) or rearrangement-reduction (path $\mathrm{C}$ ). The ring expansion yields an iminium ion (paths A and B) or a nitrilium ion (path C). All pathways are energetically accessible but paths $\mathrm{A}$ and $\mathrm{B}$ are kinetically favored at room temperature; path $\mathrm{C}$ becomes competitive in those cases where high reaction temperatures are required. Hence, a Beckmann rearrangement (path C) cannot be excluded but reduction followed by ring-expanding migration is more likely. The method indeed extends to hydroxylamine derivatives which is in agreement with the computed mechanism and control experiments. The new protocol avoids the previously used stoichiometric aluminum- and boron-based reductants.

\section{Conflicts of interest}

There are no conflicts to declare.

\section{Acknowledgements}

H. F. gratefully acknowledges the Alexander von Humboldt Foundation for a postdoctoral fellowship (2018-2020). G. W. thanks the National Natural Science Foundation of China for financial support (Grant No. 21903043). All theoretical calculations were performed at the High-Performance Computing Center (HPCC) of Nanjing University. M. O. is indebted to the Einstein Foundation (Berlin) for an endowed professorship. We thank Dr Maria Schlangen and Dr Sebastian Kemper for expert advice with the MS and NMR measurements, respectively.

\section{Notes and references}

1 J. Lam, K. M. Szkop, E. Mosaferi and D. W. Stephan, FLP catalysis: Main group hydrogenations of organic unsaturated substrates, Chem. Soc. Rev., 2019, 48, 3592-3612.

2 (a) J. Mohr and M. Oestreich, $\mathrm{B}\left(\mathrm{C}_{6} \mathrm{~F}_{5}\right)_{3}$-catalyzed hydrogenation of oxime ethers without cleavage of the $\mathrm{N}-\mathrm{O}$ bond, Angew. Chem., Int. Ed., 2014, 53, 13278-13281; (b) J. Mohr, D. Porwal, I. Chatterjee and M. Oestreich, Extending the scope of the $\mathrm{B}\left(\mathrm{C}_{6} \mathrm{~F}_{5}\right)_{3}$-catalyzed $\mathrm{C}=\mathrm{N}$ bond reduction: Hydrogenation of oxime ethers and hydrazones, Chem. Eur. J., 2015, 21, 17583-17586.

3 Cramer and co-workers recently accomplished a transitionmetal-catalyzed hydrogenation of oximes to hydroxyamines: J. Mas-Roselló, T. Smejkal and N. Cramer, Iridium-catalyzed acid-assisted asymmetric hydrogenation of oximes to hydroxylamines, Science, 2020, 368, 1098-1102.

4 (a) D. Weber and M. R. Gagné, Si-H bond activation by main-group Lewis acids, in Organosilicon Chemistry: Novel Approaches and Reactions, ed. T. Hiyama and M. Oestreich, Wiley-VCH, Weinheim, 2019, pp. 33-85; (b) M. Oestreich, J. Hermeke and J. Mohr, A unified survey of $\mathrm{Si}-\mathrm{H}$ and $\mathrm{H}-\mathrm{H}$ bond activation catalysed by electron-deficient boranes, Chem. Soc. Rev., 2015, 44, 2202-2220.

5 H. Fang and M. Oestreich, Defunctionalisation catalysed by boron Lewis acids, Chem. Sci., 2020, 11, 12604-12615.

6 For a review, see: $(a)$ H. Cho, Rearrangement of oximes and hydroxylamines with aluminum reductants, Tetrahedron, 2014, 70, 3527-3544. Selected examples involving $\mathrm{LiAlH}_{4}$ : (b) D. R. Smith, M. Maienthal and J. Tipton, Reduction of oximes with lithium aluminum hydride, J. Org. Chem., 1952, 17, 294-297; (c) R. E. Lyle and H. J. Troscianiec, Molecular rearrangements. VI. The rearrangement of oximes on reduction with lithium aluminum hydride, J. Org. Chem., 1955，20, 1757-1760; (d) M. N. Rerick, C. H. Trottier, R. A. Daignault and J. D. DeFoe, The lithium aluminum hydride - aluminum chloride reduction of oximes, Tetrahedron Lett., 1963, 4, 629-634. Selected examples involving DIBAL-H: (e) S. Sasatani, T. Miyazaki, K. Maruoka and H. Yamamoto, Diisobutylaluminum hydride a novel reagent for the reduction of oximes, Tetrahedron Lett., 1983, 24, 4711-4712; $(f)$ K. Maruoka, T. Miyazaki, M. Ando, Y. Matsumura, S. Sakane, K. Hattori and H. Yamamoto, Organoaluminum-promoted Beckmann rearrangement of oxime sulfonates, J. Am. Chem. Soc., 1983, 105, 2831-2843; (g) H. Cho, Y. Iwama, K. Sugimoto, S. Mori and H. Tokuyama, Regioselective synthesis of heterocycles containing nitrogen neighboring an aromatic ring by reductive ring expansion using diisobutylaluminum hydride and studies on the reaction mechanism, J. Org. Chem., 2010, 75, 627-636. An example with various aluminum reagents: (h) H. Cho, Y. Iwama, N. Mitsuhashi, K. Sugimoto, K. Okano and H. Tokuyama, Ring-expansion reaction of oximes with aluminum reductants, Molecules, 2012, 17, 7348-7355.

7 Selected examples involving $\mathrm{BH}_{3} \cdot \mathrm{SMe}_{2}$ : (a) M. OrtizMarciales, D. Figueroa, J. A. López, M. De Jesús and 
R. Vega, Steric and electronic effects on the reduction of $O$-silylated aromatic ketoximes with borane, Tetrahedron Lett., 2000, 41, 6567-6570; (b) M. Ortiz-Marciales, L. D. Rivera, M. De Jesús, S. Espinosa, J. A. Benjamin, O. E. Casanova, I. G. Figueroa, S. Rodríguez and W. Correa, Facile Rearrangement of $O$-silylated oximes on reduction with boron trifluoride/borane, J. Org. Chem., 2005, 70, 10132-10134.

8 C. B. Caputo and D. W. Stephan, Activation of alkyl C-F bonds by $\mathrm{B}\left(\mathrm{C}_{6} \mathrm{~F}_{5}\right)_{3}$ : Stoichiometric and catalytic transformations, Organometallics, 2012, 31, 27-30.

$9 \mathrm{H}$. Fang and M. Oestreich, Reductive deamination with hydrosilanes catalyzed by $\mathrm{B}\left(\mathrm{C}_{6} \mathrm{~F}_{5}\right)_{3}$, Angew. Chem., 2020, 59, 11394-11398.

10 Selected examples of $\mathrm{B}\left(\mathrm{C}_{6} \mathrm{~F}_{5}\right)_{3}$-catalyzed hydrosilylation of imines: (a) J. M. Blackwell, E. R. Sonmor, T. Scoccitti and W. E. Piers, $B\left(\mathrm{C}_{6} \mathrm{~F}_{5}\right)_{3}$-catalyzed hydrosilation of imines via silyliminium intermediates, Org. Lett., 2000, 2, 3921-3923; (b) D. T. Hog and M. Oestreich, B( $\left.\mathrm{C}_{6} \mathrm{~F}_{5}\right)_{3}$-catalyzed reduction of ketones and imines using silicon-stereogenic silanes: Stereoinduction by single-point binding, Eur. J. Org. Chem., 2009, 5047-5056; (c) J. Hermeke, M. Mewald and M. Oestreich, Experimental analysis of the catalytic cycle of the borane-promoted imine reduction with hydrosilanes: Spectroscopic detection of unexpected intermediates and a refined mechanism, J. Am. Chem. Soc., 2013, 135, 17537-17546.

11 (a) Y. Zhao and D. G. Truhlar, The M06 suite of density functionals for main group thermochemistry, thermochemical kinetics, noncovalent interactions, excited states, and transition elements: Two new functionals and systematic testing of four M06-class functionals and 12 other functionals, Theor. Chem. Acc., 2008, 120, 215-241; (b) Y. Zhao and D. G. Truhlar, Density functionals with broad applicability in chemistry, Acc. Chem. Res., 2008, 41, 157-167.

12 M. J. Frisch, et al., Gaussian 16, Revision A.03, Gaussian, Inc., Wallingford CT, 2016 The full citation of the Gaussian software is given in the ESI. $\dagger$

13 J. Tomasi and M. Persico, Molecular interactions in solution: An overview of methods based on continuous distributions of the solvent, Chem. Rev., 1994, 94, 2027-2094.

14 A. Y. Houghton, J. Hurmalainen, A. Mansikkamäki, W. E. Piers and H. M. Tuononen, Direct observation of a borane-silane complex involved in frustrated Lewis-pairmediated hydrosilylations, Nat. Chem., 2014, 6, 983-988.

$153 \mathrm{D}$ structures provided in the ESI $\uparrow$ were prepared using CYL View. See: C. Y. Legault, CYLview, 1.0b, Université de Sherbrooke, 2009, http://www.cylview.org.

16 (a) D. J. Parks, J. M. Blackwell and W. E. Piers, Studies on the mechanism of $\mathrm{B}\left(\mathrm{C}_{6} \mathrm{~F}_{5}\right)_{3}$-catalyzed hydrosilation of carbonyl functions, J. Org. Chem., 2000, 65, 3090-3098; (b) S. Rendler and M. Oestreich, Conclusive evidence for an $\mathrm{S}_{\mathrm{N}}$ 2-Si mechanism in the $\mathrm{B}\left(\mathrm{C}_{6} \mathrm{~F}_{5}\right)_{3}$-catalyzed hydrosilylation of carbonyl compounds: Implications for the related hydrogenation, Angew. Chem., Int. Ed., 2008, 47, 5997-6000; (c) T. Fallon and M. Oestreich, A constellation of deuterium-labeled silanes as a simple mechanistic probe not requiring absolute configuration determination, Angew. Chem., Int. Ed., 2015, 54, 12488-12491.

17 K. Sakata and H. Fujimoto, Quantum chemical study of $\mathrm{B}\left(\mathrm{C}_{6} \mathrm{~F}_{5}\right)_{3}$-catalyzed hydrosilylation of carbonyl group, J. Org. Chem., 2013, 78, 12505-12512.

18 For the reaction of $(E)$-1aa (or its reduced intermediates I3, I5, I9, and I13) with the $\mathrm{B}\left(\mathrm{C}_{6} \mathrm{~F}_{5}\right)_{3} \cdot \mathrm{PhSiH}_{3}$ complex I1, the corresponding $\mathrm{S}_{\mathrm{N}} 2$-Si transition state could not be located. After extensive scans for these processes, no electronic energy barrier was found. Some stable trigonal bipyramidal transition complexes (rather than transition states), such as I2', I4', I6', I8', I10', I11', and I14', were located (see Fig. S70 in the ESI $\dagger$ for the optimized 3D structures). These results suggest that the activation barriers of these steps mainly come from the entropy loss for trimolecular processes.

19 These transition complexes resemble the solid-state structure of the counteranion-stabilized $\mathrm{H}_{3} \mathrm{Si}^{+}$cation described by us: Q. Wu, E. Irran, R. Müller, M. Kaupp, H. F. T. Klare and M. Oestreich, Characterization of hydrogen-substituted silylium ions in the condensed phase, Science, 2019, 365, 168-172.

20 We also calculated the rearrangement of bissilyloxonium ion I6 proceeding through an alkyl migration/ $\mathrm{N}-\mathrm{O}$ bond cleavage process (Scheme 7, I6 $\rightarrow$ I15, gray color). However, this process is kinetically unfavorable because of the involvement of a high-energy transition state $\left(\Delta G^{\ddagger}=34.7 \mathrm{kcal} \mathrm{mol}^{-1}\right)$.

21 For a recent review, see: (a) K. Kaur and S. Srivastava, Beckmann rearrangement catalysis: A review of recent advances, New J. Chem., 2020, 44, 18530-18572. Selected examples: (b) M. T. Nguyen, G. Raspoet and L. G. Vanquickenborne, A new look at the classical Beckmann rearrangement: A strong case of active solvent effect, J. Am. Chem. Soc., 1997, 119, 2552-2562; (c) S. Yamabe, N. Tsuchida and S. Yamazaki, Is the Beckmann rearrangement a concerted or stepwise reaction? A computational study, J. Org. Chem., 2005, 70, 10638-10644; (d) I. Lezcano-González, M. Boronat and T. Blasco, Investigation on the Beckmann rearrangement reaction catalyzed by porous solids: MAS NMR and theoretical calculations, Solid State Nucl. Magn. Reson., 2009, 35, 120-129; (e) N. An, B.-X. Tian, H.-J. Pi, L. A. Eriksson and W.-P. Deng, Mechanistic insight into self-propagation of organo-mediated Beckmann rearrangement: A combined experimental and computational study, J. Org. Chem., 2013, 78, 4297-4302. 